\title{
Gondoic Acid
}

National Cancer Institute

\section{Source}

National Cancer Institute. Gondoic Acid. NCI Thesaurus. Code C68370.

A monounsaturated long-chain fatty acid with a 20-carbon backbone and the sole double bond originating from the 9th position from the methyl end, with the bond in the cisconfiguration. 